\title{
DIFERENTES NÍVEIS DE PERCEPÇÃO DA PAISAGEM DA LAGOA DA CONCEIÇÃO (SC) ATRAVÉS DO SIG*
}

\author{
Alina G. Santiago
}

Arquiteta, Professora Doutora do Departamento de Arquitetura e Urbanismo/UFSC

Miguel F. Bianchi Acadêmico do curso de Arquitetura e Urbanismo/UFSC. Bolsista CNPq/PIBIC

Flávia F. Feitosa Acadêmica do curso de Arquitetura e Urbanismo/UFSC. Bolsista CNPq/PIBIC

Marcelo M. Rosa Acadêmico do curso de Arquitetura e Urbanismo/UFSC. Bolsista CNPq

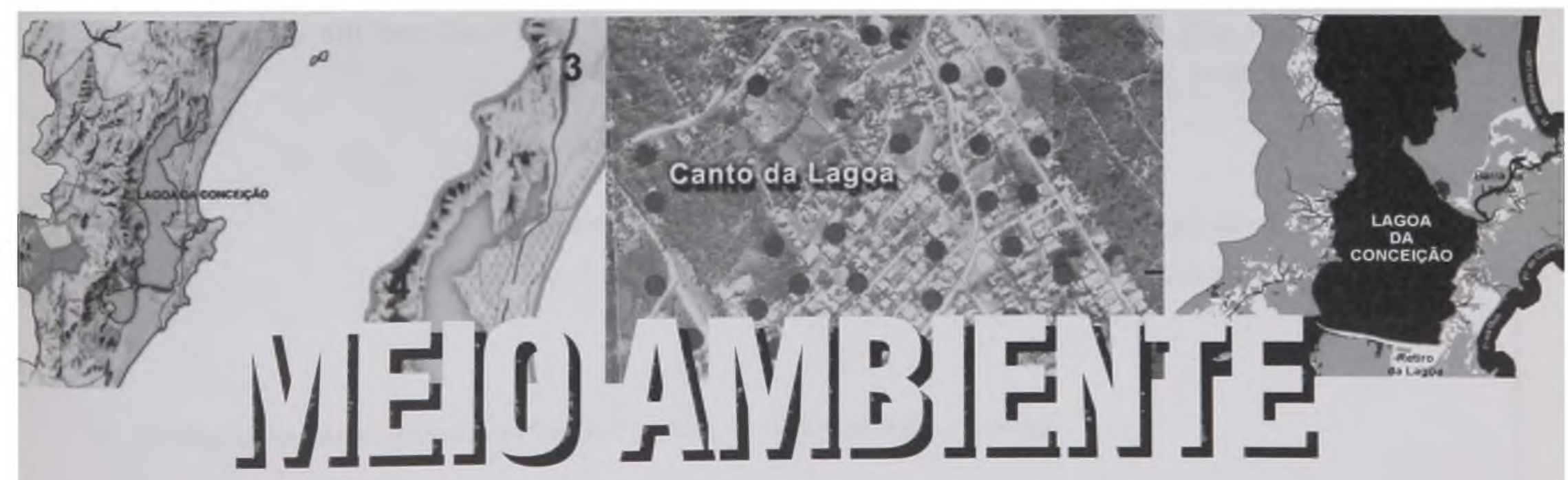




\section{RESUMO}

Muitas cidades brasileiras vêm sofrendo um acelerado processo de modificação na paisagem, decorrente do crescente processo de urbanização. A Lagoa da Conceição, em Santa Catarina, insere-se neste contexto, sendo, portanto, a área escolhida para o presente trabalho.

Este estudo busca a utilização de ferramentas que possibilitem leituras mais qualificadas da interação entre a paisagem natural e a paisagem construída. Para a elaboração do diagnóstico, diferentes escalas foram utilizadas no processo de percepção da paisagem. Na escala menor, que permite uma visão ampla da bacia hidrográfica da Lagoa da Conceição, foram identificadas as áreas a serem preservadas, as áreas apropriadas à ocupação urbana e as áreas de conflitos. A escala maior, que visualiza as áreas urbanizadas com maiores detalhes, possibilita a delimitação mais precisa e uma melhor compreensão dos conflitos apontados. Este detalhamento abrange a identificação dos agentes, dos usos e tipos de edificações mais presentes nos locais problemáticos. Entre os resultados obtidos citamos a divulgação das bases cartográficas atualizadas, a compreensão dos conflitos sociais e ambientais envolvendo o uso do solo e a elaboração de recomendações visando à futura ocupação da área.

\section{ABSTRACT}

The landscapes of many brazilian cities have undergone an accelerated process of urbanization mainly due to poor planning. One such case is the Lagoa da Conceição, located in the Island of Santa Catarina, whose sudden growth was caused by the boom of tourism and, for that reason, chosen as the pilot area for this research.

The study focuses on the search for tools that are able to provide a detailed interpretation of the interactions taking place between the natural and the man-made environments. For the spatial diagnosis, different scales of landscape perception were employed. On a general level it was possible to identify those areas that are more suitable for urban occupation, for natural preservation, and the areas of conflict over land use. On a detailed level, urbanized areas were analyzed enabling a better zoning and a clearer insight of conflicting areas. This detailing involves the identification of urban agents, and of the dominant construction types and uses in problematic areas.

Among the results obtained are the spreading of updated cartographical bases, the understanding of the social and environmental conflicts revolving around land use, and the elaboration of recommendations regarding the future occupation of the area. 


\section{DIFERENTES NÍVEIS DE PERCEPÇÃO DA PAISAGEM DA LAGOA DA CONCEIÇÃO (SC) ATRAVÉS DO SIG*}

\section{Introdução}

Em virtude de um acelerado processo de urbanização, as cidades brasileiras têm sofrido intensas modificações em sua paisagem. Novas lógicas de interação entre o ambiente natural e o construído vêm se estabelecendo e, não raramente, têm sido ditadas por legislações urbanas desenvolvimentistas.

A Lagoa da Conceição, localizada a leste da ilha de Santa Catarina, representa o caso típico, acentuado o grau e a intensidade do problema por se tratar de um ecossistema complexo e sensível. Localiza-se em um bucólico recanto de Florianópolis, cuja beleza ímpar reúne praias, dunas, montanhas e a maior lagoa da ilha.

Apesar da singularidade evidente, a bacia hidrográfica da Lagoa da Conceição é regida pelo Plano Diretor dos Balneários de 1985, uma legislação que mapeia os diferentes balneários da ilha em escala abrangente (1:10.000), indiferenciando-os entre si e ignorando uma série de questōes relevantes que deveriam ser complementadas em outra escala. Apesar de alguns locais da bacia hidrográfica como a Barra da Lagoa, Retiro da Lagoa e praia Mole já terem adquirido seu plano específico - cuja qualidade tem sido alvo de polêmicas discussões acadêmicas, governamentais e comunitárias - a Lagoa da Conceição permanece sem um plano em uma escala mais detalhada que seja capaz de levar em consideração algumas peculiaridades do sítio.

Como resultado de um antagônico processo de ocupaçāo, da falta de fiscalização e de uma legislação generalista, a 
Lagoa da Conceição tem sido vítima de uma ocupação desordenada que promove a polvição das águas, a destruição das áreas de preservação permanente, o esgotamento do sistema viário, a impermeabilização do solo em áreas de declividade acentuada e a privatização da orla. Agrava ainda mais esta problemática a demanda de turismo inerente, do qual decorre um forte acréscimo na renda munícipe, mas decorrem também grandes problemas urbanístico-sociais da itha de Santa Catarina.

Neste trabalho, desenvolvido pelo Grupo de Informática na Arquitetura (INFOARQ) da Universidade Federal de Santa Catarina (UFSC), perseguimos os seguintes objetivos:

- Possibilitar leituras mais qualificadas da interação entre a paisagem natural e a paisagem construída da Lagoa da Conceição pela interação de diferentes escalas;

- efetuar o levantamento da ocupação do solo, do mapeamento digital e da análise de características físicas da Lagoa da Conceição, identificando as áreas mais apropriadas para a ocupação ou a preservação, bem como os conflitos resultantes do uso e ocupação do solo.

\section{Metodologia}

\subsection{O SIG e a Utilização de Escalas Diferenciadas} no Processo de Percepção da Paisagem

Quando iniciado o trabalho desenvolvido pelo grupo INFOARQ/UFSC, em 1997, os dados disponíveis sobre a Lagoa da Conceição consistiam apenas em bases analógicas, muitas delas desatualizadas. Desde então, partindo da necessidade de avaliar o grau de interferência do processo urbano como promotor dos problemas locais e de gerar informaçōes capazes de subsidiar um futuro lançamento de diretrizes para a ocupação da área, as bases cartográficas e dados existentes ou coletados foram integrados por meio da utilização de um Sistema de Informações Geográficas (SIG). 
Em nosso entender, esses sistemas são um conjunto de tecnologias que realizam o tratamento computacional de dados georreferenciados, descrevendo-os quanto aos seus atributos, relações espaciais e provendo um método consistente para análise e consulta. Permitem a aquisição, edição, armazenamento, atualização e análise de dados, assim como a geração de novas informações pelo cruzamento entre dados espaciais e não-espaciais ou entre dados espaciais e espaciais (sobreposição de polígonos).

A base de seu funcionamento está em manipular planos de informações que representam um determinado elemento do mundo real sobre uma base comum. Estes planos de informações podem ser de diferentes fontes e formatos e, uma vez inseridos e integrados na base, podem ser combinados de diversas maneiras, por meio de algoritmos de manipulação e análise ou simplesmente permanecerem disponíveis para fácil consulta, visualização e plotagem.

A abordagem deste trabalho associa os Sistemas de Informações Geográficas com a utilização de diferentes escalas para uma efetiva avaliação da paisagem, já que cada uma delas resulta em percepçōes e alcances diversificados. Na escala menor (1:10.000) - que permite uma visão ampla da bacia hidrográfica da Lagoa da Conceição - foram identificadas as áreas a serem preservadas, as áreas apropriadas à ocupação urbana e as divergências desta delimitação com a situação atual. A escala maior (1:1.000), que visualiza as áreas urbanizadas mais detalhadamente, possibilita a delimitação mais precisa e uma melhor compreensão dos conflitos apontados na escala menor. Este detalhamento abrange a identificação dos agentes, dos usos e tipos de edificaçōes mais presentes nos locais problemáticos ou ainda as relaçōes existentes entre atributos diferenciados, como, por exemplo, a densidade da ocupação, a distribuição de usos, a porcentagem de edificações servidas por rede de esgoto e o índice de polvição na Lagoa. 
Para a implementação de um sistema nesses moldes, é fundamental a obtenção e a sistematização de um conjunto de dados em formato digital para que sirvam de base para as operações necessárias. Em muitos lugares são disponibilizadas bases de dados digitais, tanto cartográficos como tabulares, preparados para sua incorporação em um SIG. No contexto em que foi e está sendo realizado o presente trabalho, as condições não correspondem às descritas.

No Brasil, ainda são poucos os casos de municípios que possuem e disponibilizam mapas e dados cadastrais digitais e atualizados. Em geral, os dados disponíveis em meio digital não são preparados para se incorporar imediatamente a um SIG, necessitando ser editados preliminarmente. No caso de dados tabulares, a maior dificuldade é a falta de uma padronização quanto à codificação de lotes e edificações.

Diante de tais condições, a única opção é digitalizar dados analógicos, desde mapas até dados de levantamentos de campo, com as implicaçōes deste processo na qualidade final dos dados digitalizados, que sofrem distorções sucessivas e que podem apenas ser amenizadas. No caso de Florianópolis, mesmo as bases analógicas estão desatualizadas e a última restituição aerofotogramétrica disponível data de 1979. Assim, grande parte do trabalho foi dedicada a construir uma base de dados atualizada pela integração de diversas fontes (mapas, aerofotos, plantas cadastrais e levantamentos de campo).

\subsection{A Delimitação das Áreas de Preservação e Detecção dos Conflitos de uso na Bacia Hidrográfica da Lagoa da Conceição (1:10.000)}

Para a elaboração da base cartográfica na escala de $1: 10.000$, foram digitalizados os seguintes dados espaciais da bacia hidrográfica da Lagoa da Conceição:

- Curvas de níveis e limites naturais: digitalizados on-screen a partir da restituição aerofotogramétrica de 1979, na escala de 1:10.000, utilizando o software Autodesk CAD Overlay;

- drenagem: digitalizada on-screen a partir da restituição aerofotogramétrica de 1979 na escala de 1:10.000, utilizando o software AutoCAD R14;

- manchas de ocupação: digitalizadas no sofłware AutoCAD R14 a partir das aerofotos da área (CELESC/1998/escala 176 1:15. 000), digitalizadas pelo Projeto Floripa Digital;

- áreas legalmente protegidas (Parque Florestal do Rio Vermelho, Parque da praia da Galheta, Parque das Dunas e Mangue): digitalizadas a partir do mapa do Plano Diretor dos 


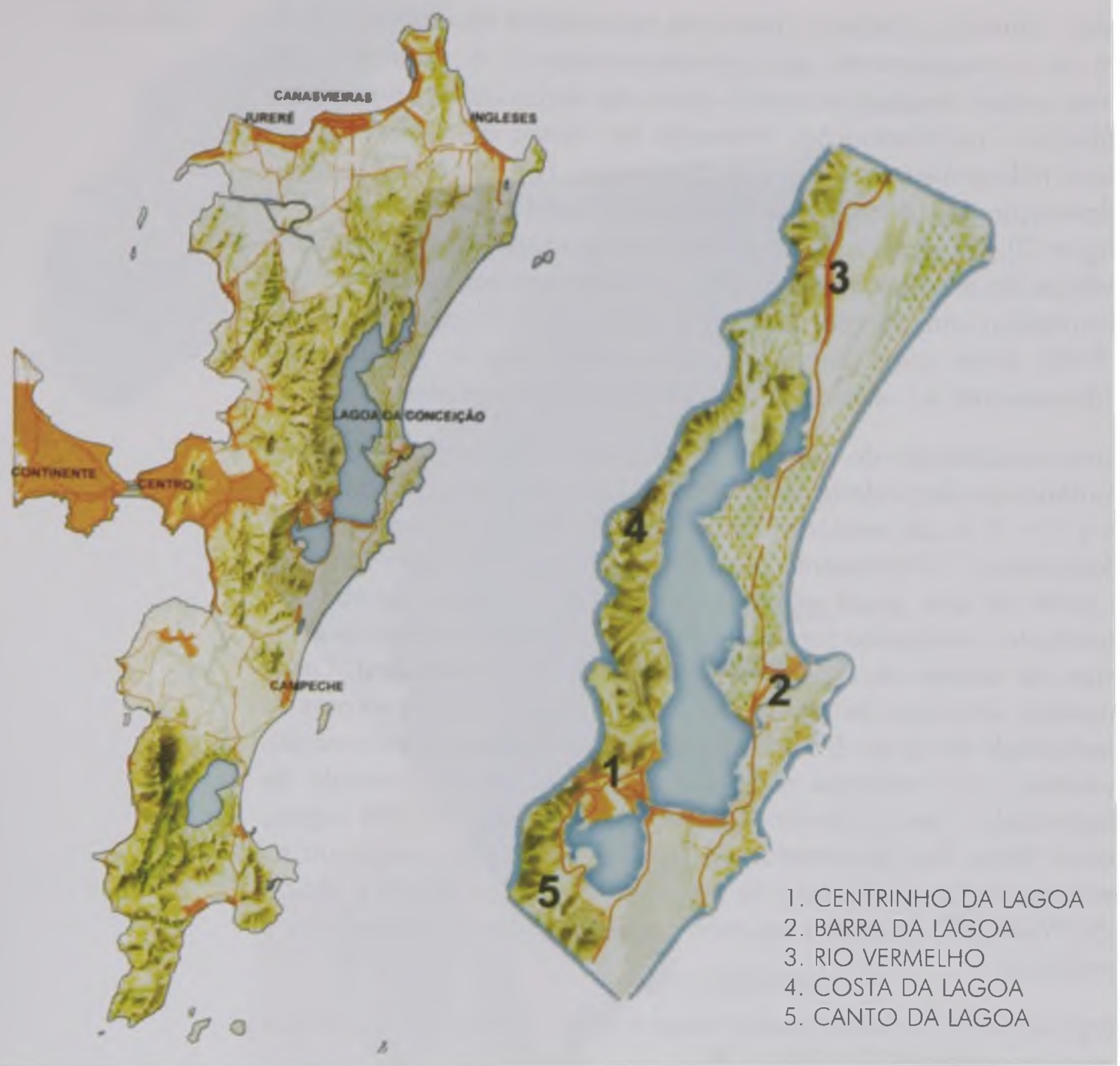

Figura 1: Localizaçāo da bacia hidrográfica da Lagoa da Conceiçāo na liha de Santa Catarina Fonte: Arquivo INFOARQ

Balneários na escala de 1:10.000 e dos planos diretores específicos da Barra da Lagoa e da praia Mole.

O SIG utilizado para a integração desses dados foi o SPRING 3.4 (Sistema de Processamento de Informações Georreferenciadas), software de domínio público desenvolvido pelo Instituto Nacional de Pesquisas Espaciais (INPE).

Partindo da avaliação do plano diretor vigente na Lagoa da Conceição, nota-se que importantes áreas non aedificandi não estão presentes no mapeamento de áreas legalmente protegidas, como, por exemplo, as faixas de proteção ao longo dos cursos d'agua, da orla do mar e da lagoa. A preocupação com uma delimitação mais cuidadosa das áreas non aedificandi somente é verificada nas áreas da bacia hidrográfica que já contam com planos diretores específicos e ainda assim, em muitas delas, a faixa não foi adequadamente delimitada em virtude da ocupação em estágio avançado, desrespeitando leis ambientais federais, estaduais e até a própria legislação municipal. 
Desta maneira, o trabalho partiu da necessidade de elaboração de um novo mapeamento que complementasse $\circ$ já existente. Para tanto, seriam necessárias ainda - além dos dados obtidos nos órgãos públicos - as informações referentes às classes de declividade da bacia hidrográfica da Lagoa da Conceição. Para a produção desta informação foi utilizada a Modelagem Digital de Terreno - MDT (Figura 2). Os modelos digitais de terreno são representações matemáticas da distribuição espacial de uma determinada característica vinculada a uma porção da superfície terrestre (Câmara e Medeiros, 1998). Entre suas inúmeras aplicações estão a visualização tridimensional e a elaboração de mapas de declividades.

Para a elaboração do mapa de declividades, foi gerada uma grade numérica de declividade no software Spring com resolução de $X=5$ $\mathrm{m}$ e $\mathrm{Y}=5 \mathrm{~m}$ do território. Partindo desta grade, foi realizado um "fatiamento". O fatiamento consiste em gerar uma imagem temática a partir de uma grade retangular numérica. Os temas da imagem resultante - indicados com diferentes cores - correspondem a intervalos de valores de cotas (no caso, cotas de declividades). Desta maneira, um plano de informação numérico (a grade com valores de declividade de 5 em 5 metros) originará um plano de informação temático, com manchas contendo classes de mesmo intervalo de declividade. Para a contribuição da base cartográfica da Lagoa, foram feitos dois fatiamentos diferenciados, um deles seguindo as recomendações do Instituto de Pesquisas Tecnológicas do Estado de São Paulo (IPT) e o outro segundo as normas adotadas pelo IBGE e prefeitura.

Segundo o IPT, a definição das faixas a serem discriminadas adota $\circ$ seguinte sistema (IPT, 1991):

- 0 - 15\%: inclinação máxima longitidinal tolerável nas vias para circulação de veículos;

- 15 - 30\%: sendo $30 \%$ a declividade máxima prevista, em lei, para

o parcelamento do solo;

- 30 - 45\%: sendo $45 \%$ o limite de declividade aceitável para a ocupação;

- acima de $45 \%$.

Segundo a classificação adotada pelo IBGE, a definição das faixas é a seguinte:

- 0 - 3\%: plano;

- 3 - 8\%: suavemente ondulado;

- 8-20\%: ondulado;

- $20-45 \%$ : fortemente ondulado;

- 45 - 75\%: montanhoso;

- acima de 75\%: escarpado. 


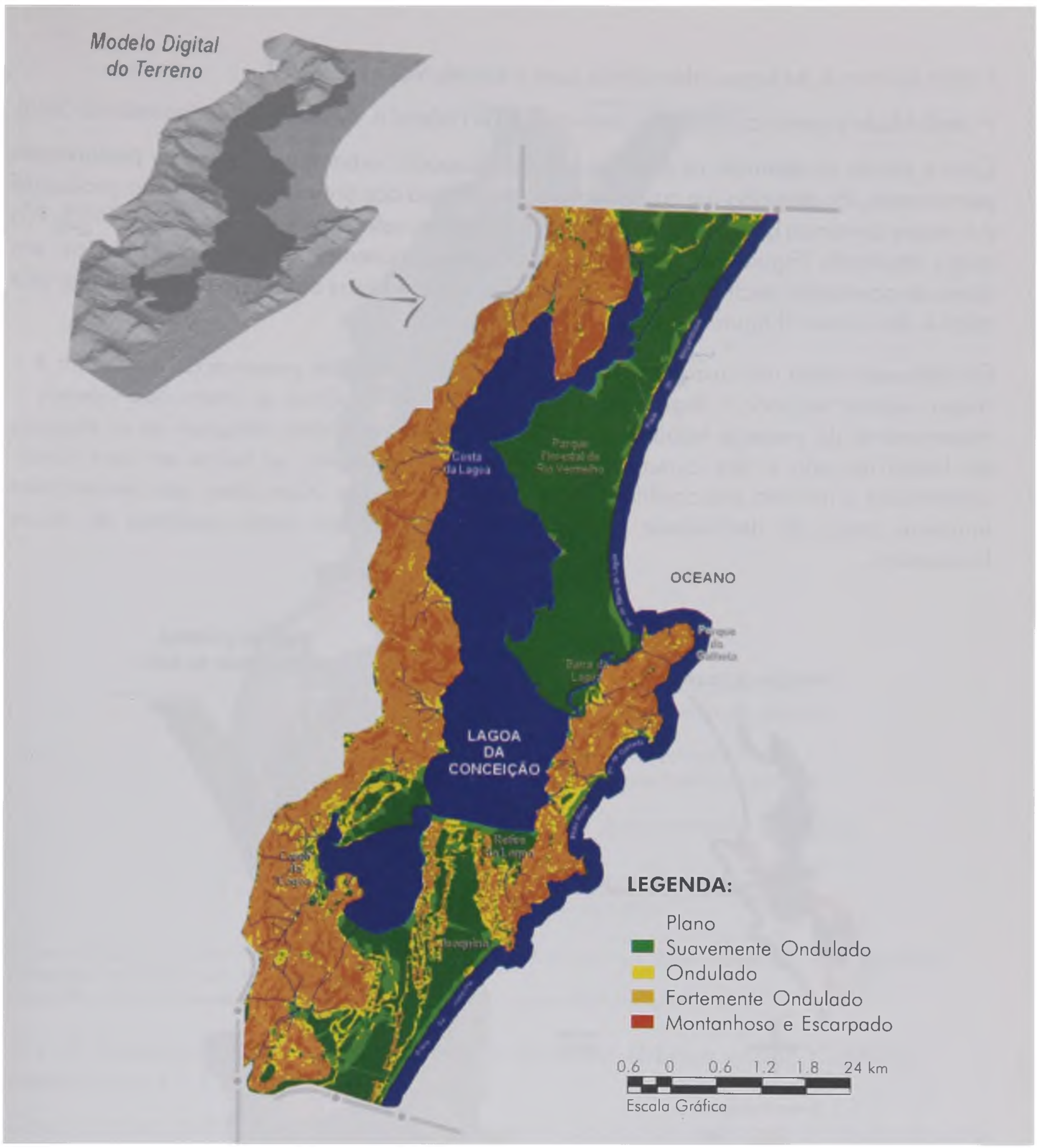

Figura 2: Mapa de declividades segundo a classificação adotada pelo IBGE, gerado a partir do Modelo Digital do Terreno da Lagoa da Conceição

Fonte: Base cartográfica original do Instituto de Planejamento Urbano de Florianópolis

$\mathrm{Na}$ confecção do mapa com áreas legalmente protegidas foram discriminadas as seguintes classes:

- Parque Florestal do Rio Vermelho, parque da praia da Galheta, parque das Dunas, mangue e promontórios, digitalizadas a partir do Mapa do Plano Diretor dos Balneários/IPUF;

- terço superior das encostas, de acordo com a Resolução CONAMA 004/85;

- nascentes, de acordo com a Lei Federal n. 1803/89 (Código Florestal);

- cursos d'água, de acordo com a Lei Federal n. 6766/79 (Parcelamento do Solo); 
- orla do mar e da lagoa, de acordo com a Lei Municipal n. 2193;

- declividade superior a 30\%, de acordo com a Lei Federal n. 6766/79 (Parcelamento do Solo).

Com o intuito de delimitar os conflitos entre a ocupação urbana e as áreas de preservação permanente, foi efetuado um cruzamento entre o mapa das áreas de preservação produzido e o mapa contendo as manchas de ocupação urbanas retiradas das aerofotos de 1998. No mapa resultante (Figura 3), destacam-se os conflitos existentes no parque das Dunas, em áreas de acentuada declividade na costa da Lagoa e nas faixas de preservação ao longo das orlas e dos cursos d'água.

Foi efetuado ainda um cruzamento entre o mapa das áreas de preservação produzido e o mapa vigente segundo a legislação municipal (Figura 4). Entre as áreas que apenas o mapeamento do presente trabalho indica como áreas protegidas, destacam-se as situadas ao longo da orla e dos cursos d'água, que são justamente os locais em que foram constatados a maioria dos conflitos com a ocupação urbana. Além disso, são demarcadas inúmeras áreas de declividade acentuada que representam locais passíveis de riscos localizados.

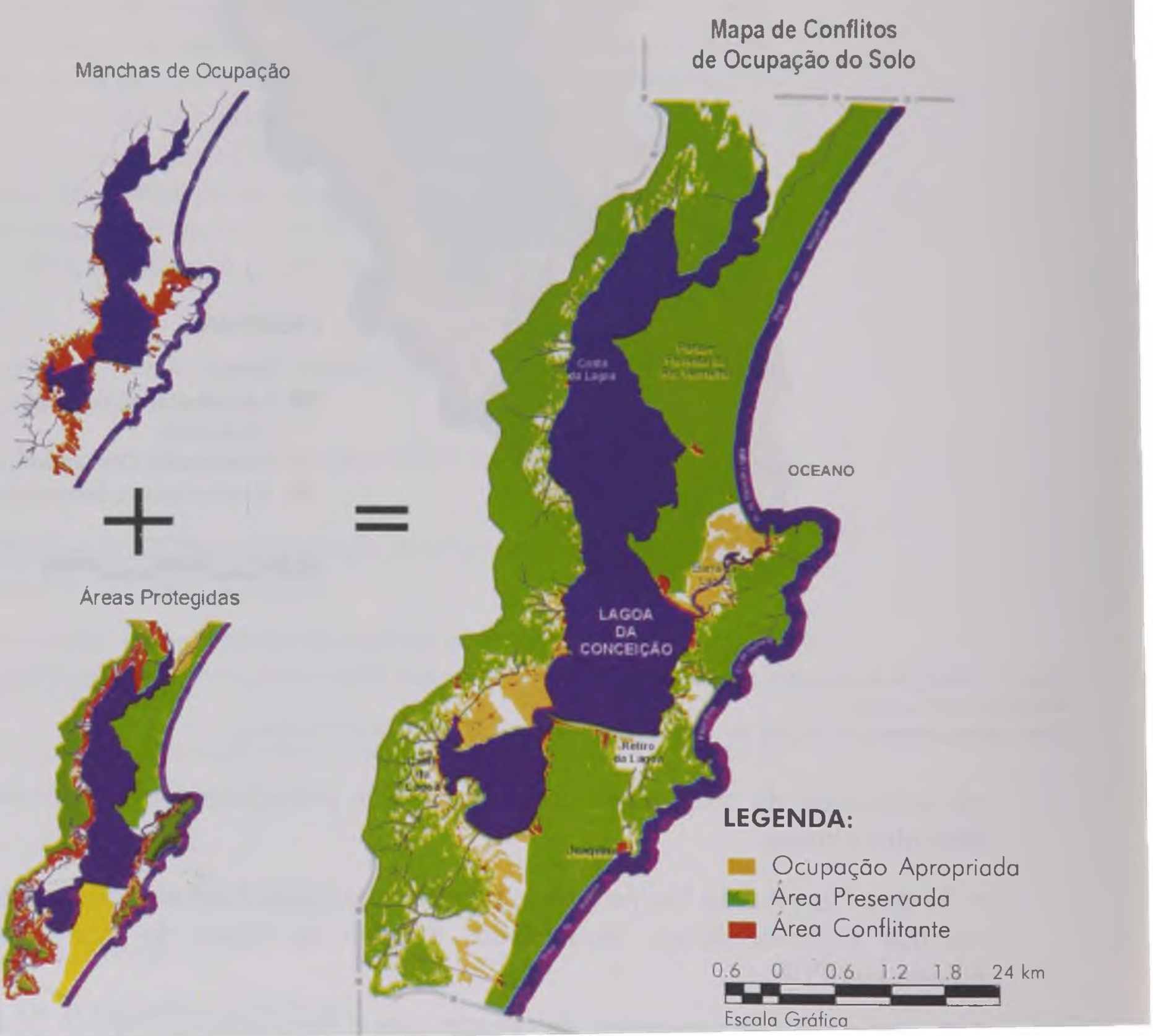

Figura 3: Mapa de conflitos de ocupaçāo do solo, gerado a partir do cruzamento dos mapas de áreas protegidas e manchas de ocupaçāo

Fonte: Base cartográfica original do Instituto de Planejamento Urbano de Florianópolis 


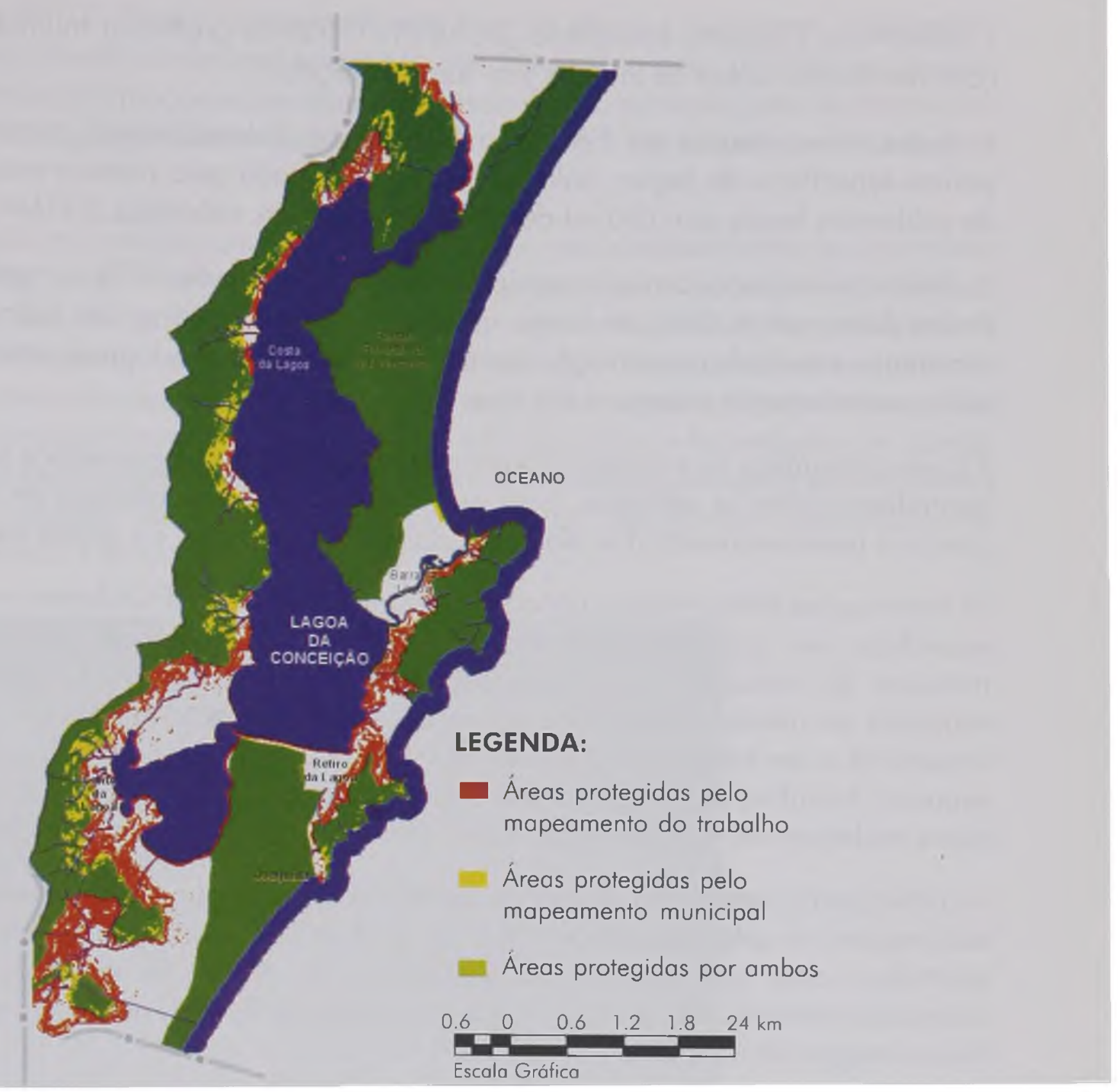

Figura 4: Mapa de cruzamento entre as áreas legalmente protegidas pelo plano diretor vigente e as áreas legalmente protegidas, delimitadas pelo trabalho

Fonte: Base cartográfica original do Instituto de Planejamento Urbano de Florianópolis

\subsection{O Detalhamento e a Compreensão da Área Urbana e dos Conflitos Detectados (1:1.000)}

Detectados os conflitos de uso do solo existentes na bacia hidrográfica, a utilização de uma escala maior (1:1.000) permite a caracterização dos mesmos. Neste contexto, o SIG pode ser utilizado na compreensão do processo em curso, permitindo a identificação de relações entre atividade turística, uso e ocupação do solo, a estrutura urbana existente e os condicionantes naturais. Com este intuito, foi elaborado um mapeamento das atividades urbanas e dos equipamentos turísticos, a fim de estabelecer, de forma mais clara, a sua distribuição espacial.

Para a elaboração da base cartográfica desta etapa do trabalho, foram utilizados os seguintes dados espaciais da bacia hidrográfica da Lagoa da Conceição:

- Limites naturais e eixos viários: digitalizados a partir da restituição aerofotogramétrica de 1979 na escala de 1:10.000;

- aerofotos da área (CELESC/1998/escala 1:15. 000);

- plantas cadastrais de quadras (1:1.000); 
- Boletim de Cadastro Imobiliário (BCl-IPUF/1998) da prefeitura municipal com informaçōes detalhadas sobre os imóveis (em formato digital);

- dados alfanuméricos da FATMA a respeito da balneabilidade: amostras retiradas de pontos específicos da lagoa, balneabilidade mensurada pelo número mais provável (NMP) de coliformes fecais por $100 \mathrm{ml}$ de amostra das águas coletadas (FATMA, 2000);

- dados coletados in loco pela equipe INFOARQ no ano de 1998 e inseridos no banco de dados (Microsoft Access), de forma manual, contendo informações sobre usos, gabaritos, materiais e estado de conservação das edificações e nome dos logradouros com informações sobre pavimentação e largura das vias.

A base cartográfica foi montada a partir da restituição aerofotogramétrica sobre a qual foram georreferenciadas as aerofotos, para que fosse possível a atualização de algumas informações e o posicionamento das plantas cadastrais de quadras, na escala de 1:1.000.

As informações alfanuméricas obtidas no levantamento da FATMA foram vinculadas às áreas específicas em que estas ocorrem, enquanto, para as demais informações, diferentes métodos de vinculação de dados cadastrais foram testados em função das unidades espaciais de análise. Para uma análise de uso e ocupaçāo do solo, a informação mais importante a ser buscada é a ocorrência de algum fenômeno em relação a uma unidade espacial. Inicialmente, foram adotadas as quadras como unidades de análise, a partir das quais poderiam ser obtidas saídas como porcentagens de usos e densidade de ocupação.

A confecção do sistema nas áreas com estrutura urbana linear e com relevo acidentado exigiu adaptações na sistemática de análise, na qual os trechos de logradouros passaram a ser adotados como unidades de análise (Figura 5). Assim, foram utilizados métodos de vinculação de atributos à nova unidade e os dados do Boletim de Cadastro Imobiliário (BCl) foram integrados no SIG.

Boletim de Cadastro Imobiliário do IPUF é um banco de dados contendo informações detalhadas sobre edificações e lotes, elaborado com a finalidade de auxiliar na cobrança de

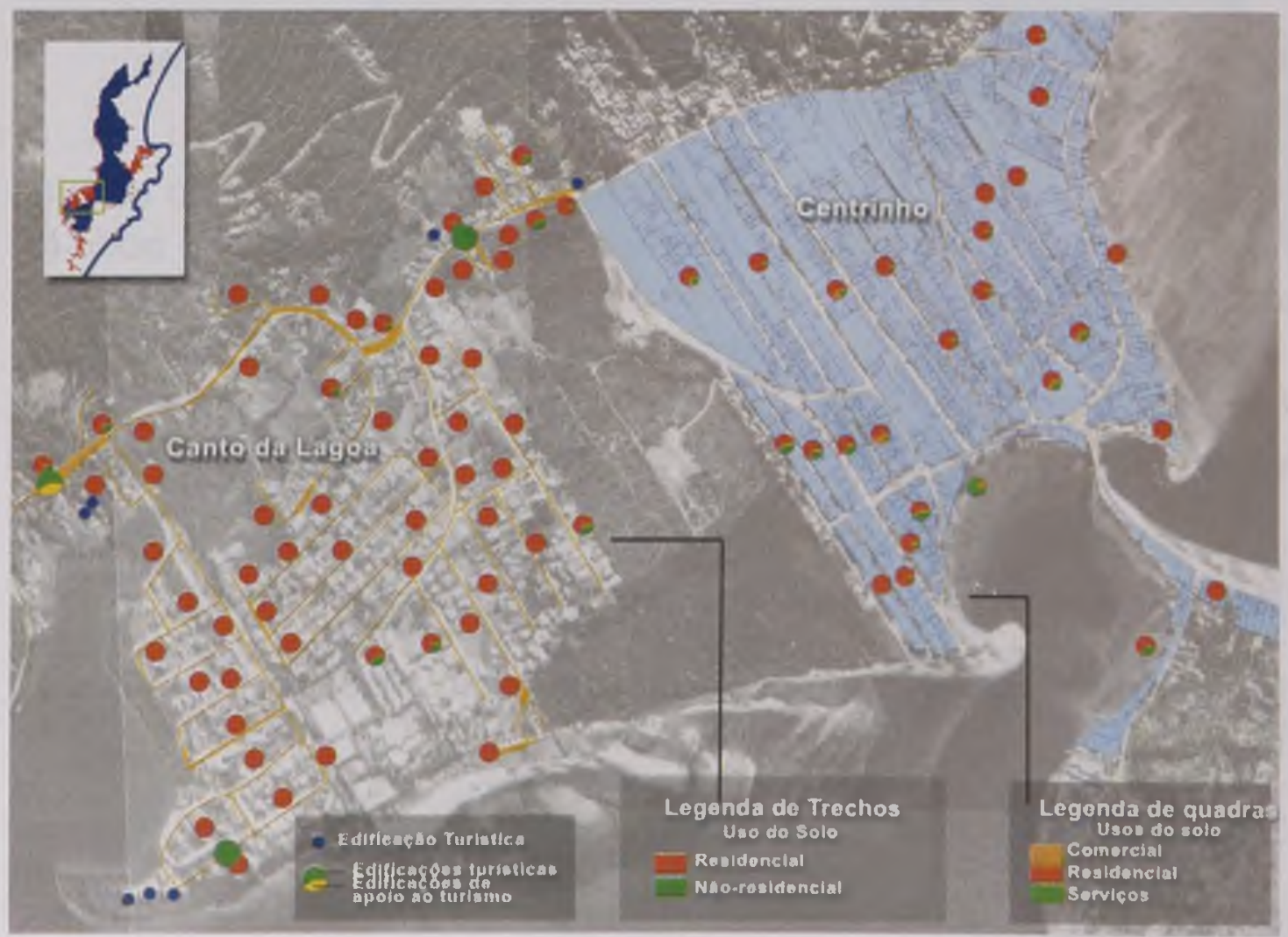

Figura 5: Mapa de distribuiçōo de usos com os diferentes tipos de vinculaçāo (quadras e trechos de ruas) Fonte: Base: Aerofotol Celesc/1998 
impostos urbanos (IPTU). Possui correspondência com as plantas cadastrais, utilizando o mesmo sistema de numeração de lotes e logradouros. Ele passou a ser utilizado por possuir grande quantidade de informações e por estar já em meio digital, evitando gasto de tempo com trabalho manual de digitação destes dados, além de ser uma fonte oficial, com atualização periódica.

Para cada edificação foi atribuído um código de trecho por meio da elaboração de uma tabela auxiliar, informando quais intervalos de lotes das quadras, pelas quais o trecho passa, pertencem a ele. Isso foi possível porque em cada registro do $\mathrm{BCl}$ estão presentes as informações do distrito, setor, quadra, número do lote e o código do logradouro a que pertence cada unidade. Posteriormente, foi realizado o cruzamento entre a tabela principal e a auxiliar, por meio de um campo em comum, que é o código do logradouro, e foi atribuído um código de trecho para cada edificação, composto pelo código de logradouro acrescido de um número seqüencial. Desta maneira, realizamos contagens automáticas, bem como a vinculação entre os objetos do desenho e o banco de dados.

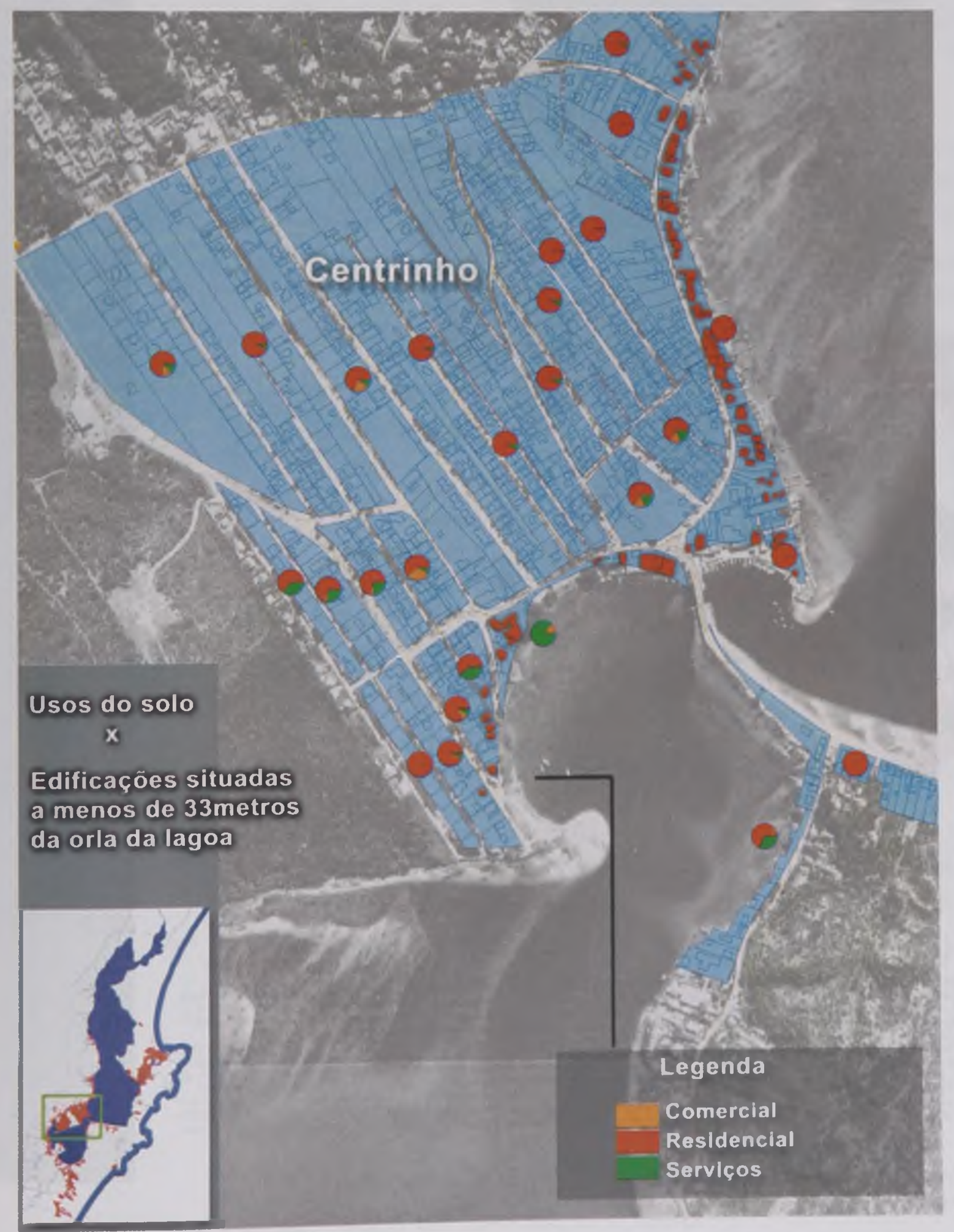

Figura 6: Mapa

indicando a

porcentagem dos usos do solo por quadras e evidenciando as edificaçōes a menos de 33 metros da orla 


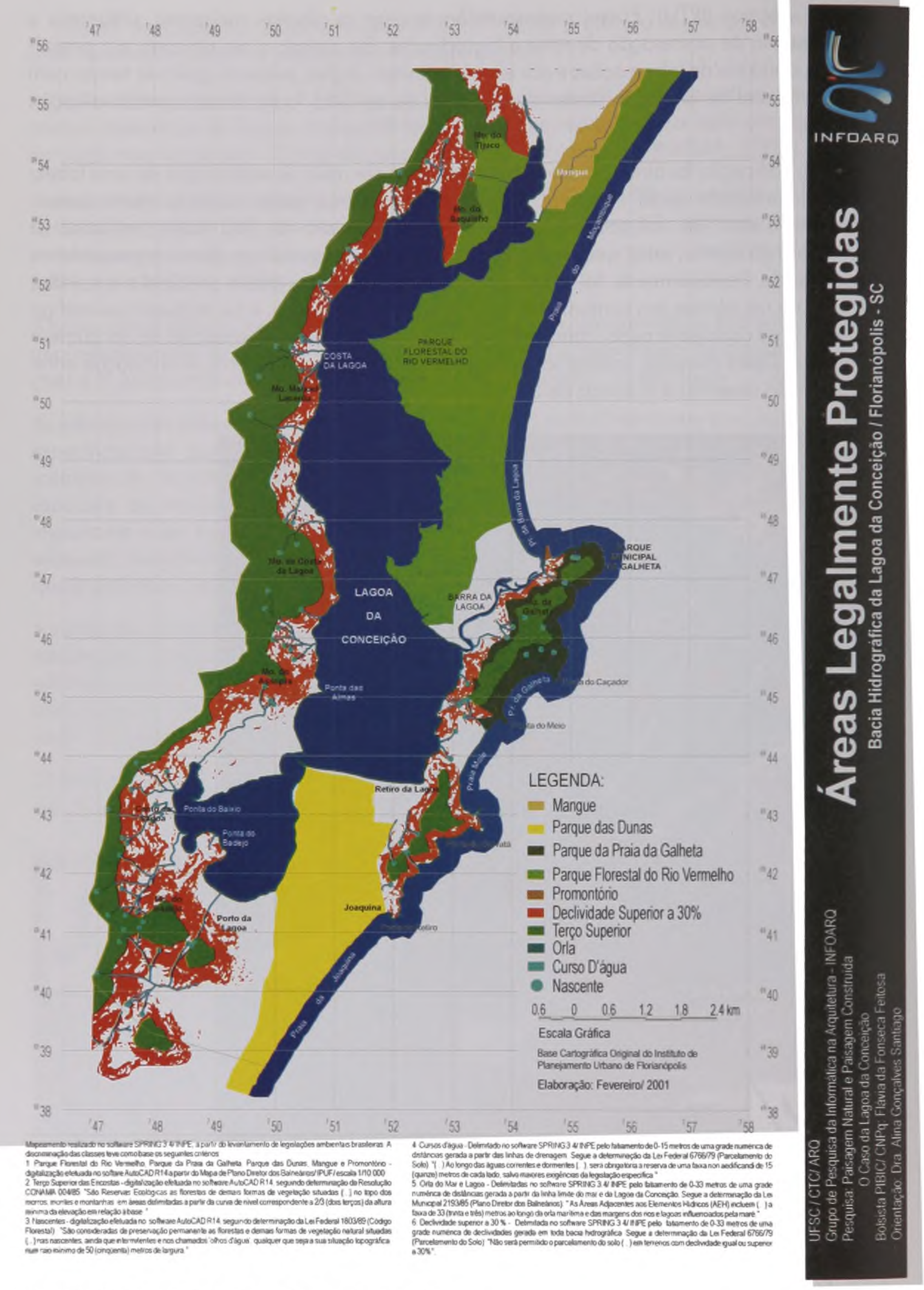

Figura 7: Página do encarte com um mapa temático da área

Diferentes Niveis de Percepção da Paisagem da Lagoa da Conceiçáo (SC) através do SIG 


\section{Análise dos Resultados e Conclusões}

Pelas bases de dados em escala 1:10.000 e 1:1.000, é possível analisar os conflitos existentes na Lagoa da Conceição sob óticas diferenciadas. Na escala mais abrangente $(1: 10.000)$, foram delimitadas as áreas a serem preservadas ou ocupadas no âmbito de toda a bacia hidrográfica, assim como os conflitos de uso do solo e áreas propícias para a expansão urbana.

Partindo deste entendimento, na escala 1:1.000 foram elaborados mapas temáticos que tratam com mais detalhes de uma amostra significativa de ocupação, envolvendo ocupaçōes projetadas (loteamentos) e espontâneas, terrenos planos e de encostas, em situação conflituosa em relação ao meio ambiente ou não.

Nos mapas, a diferença na espessura das linhas representa a densidade da ocupação (Figura 5). Associados a esta informação, aparecem gráficos mostrando a distribuição dos eventos nos respectivos trechos. Entre os eventos discriminados podemos citar:

- Distribuição de usos: identifica locais com concentração de usos comerciais e serviços, e a relação destes com a presença de edificações turísticas e, principalmente, com a ocupação em locais inadequados (Figura 6). A figura 5 mostra a distribuição de usos a partir de duas unidades espaciais: quadras (Centrinho) e trechos de logradouros (canto da Lagoa);

- sistema coletivo de esgoto: mostra os lugares onde há sistema coletivo de tratamento de esgoto, e sua época de construção. Permite a realização de associações com a densidade de ocupação, os usos existentes e dados sobre balneabilidade da Lagoa;

- mapa temporal de edificações: identifica as épocas de construção em cada trecho, distinguindo a ocupação mais antiga ao longo da via principal e a mais recente nos loteamentos e nas encostas, em trechos ainda pouco densos. Isto indica uma tendência recente de ocupação de determinadas áreas e as áreas com maior probabilidade de renovaçāo.

Como resultado do trabalho desenvolvido, podemos citar:

- Detecção e avaliação das incompatibilidades de uso e ocupação do solo na área, a compreensão dos principais agentes promotores dos conflitos detectados e a identificação de tendências futuras de ocupação e renovação. Nas áreas de conflito, salientamos os usos residenciais na orla e nas encostas, e os usos turísticos na orla;

- confecção da base de dados a ser utilizada na continuidade do trabalho, que envolve a elaboração de uma proposta de plano diretor específico para a área;

- confecção de um encarte de publicação dos mapas temáticos digitais da Lagoa da Conceição (Figura 7). 


\section{Bibliografia}

FATMA. Projeto de balneabilidade das praias e lagoas catarinenses. Florianópolis, 2000. Disponível em: www.fatma.sc.gov.br.

INSTITUTO DE PESQUISAS TECNOLÓGICAS DO ESTADO DE SÃO PAULO - IPT. Manual de ocupação de encostas. São Paulo: IPT, 1991.

CÂMARA, G. MEDEIROS, J. S. (Org.). Geoprocessamento para projetos ambientais. São José dos Campos-SP: INPE, 1998. 